\title{
Appendicitis and gastric perforation in eosinophilic granulomatosis with polyangiitis: A case report
}

\section{Gianfranco Gioia* \\ Department of Clinical Medicine, Sapienza University of Rome, Italy}

\section{Introduction}

Eosinophilic granulomatosis with polyangiitis (EGPA), formerly named Churg Strauss syndrome, is a systemic small and mediumsized-vessel vasculitis with a prevalence ranging from 10.7 to 13 cases/million inhabitants, and an annual incidence from 0.5 to 6.8 new cases/million inhabitants. EGPA may affect all ages with no sex predominance. Mean age at diagnosis is 48 years. EGPA commonly arises with asthma, allergic rhinitis, pulmonary infiltrates, and peripheral eosinophilia. Vasculitis manifestations (mononeuritis multiplex, purpura etc.) may also be the onset of EGPA [1]. Antineutrophil cytoplasm antibodies (ANCA) are present from 30 to $40 \%$ of EGPA patients. ANCA-positive status is more often associated with peripheral neuropathy, renal involvement with glomerulonephritis, and biopsy-proven granulomatous vasculitis. ANCA-negative status is more often associated with fever and heart disease [2]. EGPA treatment for both induction of remission and remission maintenance consists of glucocorticoids combined with either conventional or biologic agents [3]. The revised five-factor score (FFS) devised by the French Vasculitis Study Group is a scoring system to quantify disease severity and establish initial management and treatment [4]. Glucocorticoids alone is the treatment for non-severe disease (FFS 0) [5]. A remissioninduction regimen combining glucocorticoids and an additional immunosuppressant (e.g. cyclophosphamide) is the treatment for patients with severe disease manifestations such as mononeuritis multiplex (FFS 2 or FFS 1 with central nervous system or cardiac involvement). Induction therapy based on methotrexate or azathioprine in place of cyclophosphamide may be used in mild to moderate disease severity. Maintenance therapy (with azathioprine or methotrexate) is recommended for patients with life- and/or organ-threatening disease manifestations [6]. Rituximab is the treatment for selected ANCApositive patients with renal involvement or refractory disease [7]. Plasma exchange is the treatment for selected patients with ANCA and rapidly progressive glomerulonephritis or pulmonary-renal syndrome. Intravenous immunoglobulins is a second-line therapy for patients on glucocorticoids (and/or other immunosuppressants) with EGPA flares refractory to other treatments or during pregnancy. Interferonalpha is a second- or third-line drug for selected patients. Leukotrienereceptor antagonists can be prescribed, if needed, for EGPA patients [8]. A promising future therapy is mepolizumab [9]. EGPA may affect pulmonary, cardiovascular, nervous, cutaneous, ophthalmologic, and gastrointestinal systems. This systemic ANCA-associated vasculitides may develop life-threatening major organ involvement, such as eosinophilic pulmonary infiltration, neuropathy, acute nephritis, myocarditis, and gastrointestinal (GI) tract involvement. Even though GI symptoms are common (31-45\% of cases), GI lesions are present in only $20 \%$ of cases. GI manifestations (intestinal inflammation, hemorrhage, ulceration, perforation, bowel ischemia) are possibly due to mesenteric vasculitis and bowel wall infiltration by eosinophils [10]. GI life-threatening sequelae make early management crucial to improve long-term morbidity and mortality [11].

\section{Case report}

A male-aged 23-year complained of persistent dry cough, rhinitis and fever for 2 months despite antibiotic therapy. The patient went to hospital because of abdominal pain in right iliac fossa and hypereosinophilia. During hospitalization, he underwent laparoscopic appendectomy but abdominal pain and hypereosinophilia persisted in the following days. Blood analysis were: hemoglobin $13 \mathrm{mg} /$ $\mathrm{dL}$, total leukocyte count 17000 cells $/ \mathrm{mm} 3$ (neutrophils $47.8 \%$, lymphocytes $9.5 \%$, monocytes $5.2 \%$, and eosinophils $37.5 \%$ ), platelet count 559000 cells $/ \mathrm{mm} 3$, absolute eosinophil count 6370 cells $/ \mathrm{mm} 3$, serum immunoglobulin E level $2830 \mathrm{mg} / \mathrm{dl}$, glutamate-oxaloacetate transaminase $50 \mathrm{U} / \mathrm{L}$, glutamate-pyruvate transaminase $64 \mathrm{U} / \mathrm{L}$, gamma glutamyltransferase $85 \mathrm{U} / \mathrm{L}$, serum amylase $339 \mathrm{U} / \mathrm{L}$, and serum lipase $421 \mathrm{U} / \mathrm{L}$. Peripheral blood smear showed hypereosinophilia (eosinophils 55\%) and no dysplastic eosinophils or blasts. Serologic testing for toxocariasis and human immunodeficiency virus (HIV), specific IgE and IgG dosages for Aspergillus spp., search for Aspergillus spp. in sputum and bronchoalveolar lavage fluid were negative. Tryptase and vitamin B12 dosages were normal. Anti-nuclear antibodies (ANA), extractable nuclear antigen antibodies (ENA), anti-cardiolipin antibodies (ACA), anti-double-stranded DNA antibody (A-ds DNA), and anti-neutrophil cytoplasm antibodies (ANCA) testing (with indirect immunofluorescence and enzyme-linked immunosorbent assays) were negative. Urinalysis showed hemoglobinuria (hemoglobin ++ ), urine $\mathrm{pH} 7$, and 3-5 erythrocytes per high power field in the urinary sediment. The patient was allergic to nickel sulfate and parietaria. $\mathrm{He}$ had no signs on physical examination. Respiratory system examination revealed no pathological find. Nervous system examination revealed no sensory or motor loss. Pulmonary function test showed reversible airway obstruction. Normal cardiac function was found on echocardiography. Chest and abdomen computed-tomography (CT) scans showed bilateral mixed interstitial patchy alveolar opacities, bilateral groundglass opacities, high-density pulmonary consolidations in the left subpleural postero-basal segment of the right lower lobe, and free air between bowel loops. Esophagogastroscopy revealed deep and wide ulceration in the distal gastric body and antrum treated by

Correspondence to: Gianfranco Gioia, Department of Clinical Medicine, Sapienza University of Rome, Viale dell'Università, 37-00185 Rome, Italy; E-mail: gioiag86@hotmail.it

Received: December 02, 2017; Accepted: December 15, 2017; Published: December 19,2017 
explorative laparotomy and suture on the stomach lesser curvature of an area of about four squared centimeters. Histological specimen of cecal appendix revealed eosinophilic vasculitis thus leading to EGPA diagnosis. The wall of the cecal appendix showed small-vessel vasculitis with inflammatory infiltrate composed predominantly of eosinophils, necrotizing epithelioid granulomas surrounded by eosinophils, and some thrombosed vessels. Corticosteroid daily intravenous infusion of methylprednisolone ( $20 \mathrm{mg}$ the 1 st day, $40 \mathrm{mg}$ the 2 nd day and 60 $\mathrm{mg}$ the 3rd day) was followed by oral prednisone $(25 \mathrm{mg}$ bid) with consequent improvement of general status and reduction of eosinophil count. Therapy with cyclophosphamide with a dosage of $750 \mathrm{mg} / \mathrm{square}$ meter of body-surface area every 3 weeks (for 4 cycles) was started with good response within three months of treatment. After 2 weeks of corticosteroid therapy, blood analysis were hemoglobin $16 \mathrm{mg} / \mathrm{dl}$, total leukocyte count 12700 cells $/ \mathrm{mm} 3$ (neutrophils 63\%, lymphocytes $15 \%$, monocytes $1 \%$ and eosinophils $21 \%$ ), platelet count 252000 cells/ $\mathrm{mm} 3$, erythrocyte sedimentation rate (ESR) $70 \mathrm{~mm} /$ hour, and absolute eosinophil count 2667 cells $/ \mathrm{mm} 3$. Immunoglobulin E level was $>1000 \mathrm{mg} / \mathrm{dL}$. Renal and liver function tests were normal. Creatinine phosphokinase (CPK) was $55 \mathrm{U} / \mathrm{L}$. CPK-MB was normal and Troponin T-test was negative. There were no cysts and ova in stools. Spirometry was normal. Due to the presence of itching and erythematous lesions around the surgical scar, he was administered $4 \mathrm{mg}$ of chlorphenamine maleate per os every 4-6 hours for 5 days. Corticosteroid therapy was tapered after the disappearance of symptoms. After 3 months from the start of steroid administration, the following therapy was prednisone $37.5 \mathrm{mg}$ once a day per os for the fourth month and methotrexate at an initial dose of $15 \mathrm{mg} /$ week per os. Prednisone was given at an oral dose of $0.5 \mathrm{mg} / \mathrm{kg} /$ day for month $5,0.25 \mathrm{mg} / \mathrm{kg} /$ day for month 6 , and then gradually tapered to $5 \mathrm{mg} /$ day by month 7 . At month 2 , esophagogastroscopy reported two oval partially healing peptic ulcers about $0.8 \mathrm{~cm}$ in average diameter. At month 3, esophagogastroscopy reported only slight hyperemia of the gastric mucosa. After 4 months of treatment, blood tests were hemoglobin $15.5 \mathrm{mg} / \mathrm{dl}$, total leukocyte count 6480 cells $/ \mathrm{mm} 3$ (neutrophils $51 \%$, lymphocytes $30 \%$, monocytes 9.7\% and eosinophils 9.3\%), platelet count 238000 cells/mm3, ESR 2 $\mathrm{mm} / \mathrm{hr}$, ferritin $81 \mathrm{mg} / \mathrm{dL}$, and absolute eosinophil count 600 cells/ $\mathrm{mm} 3$. ANCA and ANA were negative. C-reactive protein was normal. Spirometry and diffusing capacity of the lungs for carbon monoxide (DLCO) were normal. After 7 months, the therapy was prednisone $5 \mathrm{mg}$ once a day alternate a day and methotrexate $15 \mathrm{mg} /$ week but presented again with dry cough and hypereosinophilia (eosinophil count 1930 cells $/ \mathrm{mm} 3$ ). Chest X-ray showed multiple nodular opacities. Chest CT reported diffuse interstitial ground glass appearance more evident in the apical segments. The patient received again intravenous methylprednisolone $60 \mathrm{mg}$ once a day for two days and then he started prednisone $25 \mathrm{mg}$ once a day. There was periodical increase of eosinophil count up to 1720 cells/mm 3 and dry cough but, at month 9 , blood analysis and clinical state were again normal. Follow-up consisted of normal esophagogastroscopy, gastric biopsy with mild helicobacter negative chronic gastritis, rhinoscopy showing nasal eosinophilic allergic polyps, CT scan of the paranasal sinuses showing nasal polyps and pansinusitis, chest CT showing a light interstitial pattern of disease, normal spirometry, normal DLCO, and normal computerized bone mineralometry. At year 1, blood tests showed normal eosinophil count (610 cells $/ \mathrm{mm} 3$, i.e. $8.9 \%)$. Capillaroscopy showed mild non-specific vascular damage. The administration of MTX ended and maintenance therapy was only oral prednisone in tapering doses to $7.5 \mathrm{mg}$ once a day. At year 2, CT scan of the paranasal sinuses reported pansinusitis and chest CT was normal with no recurrence of symptoms.

\section{Clinical implications}

Diagnostic criteria for EGPA includes asthma, eosinophilia, history of allergy, non-fixed pulmonary infiltrates, paranasal sinus abnormalities, extravascular eosinophils (1). Our patient satisfied four of these six criteria, i.e. the presence of eosinophilia, vasculitis involving the appendix, nasal polyps, pansinusitis, ground-glass opacities on chest CT. We found no cardiac and neurological involvements that occur frequently in EGPA. This case report is particular for the presence of eosinophilic appendicitis and gastric perforation. Corticosteroid plus adjuvant immunosuppressant therapy was the first-line treatment. Early corticosteroid and immunosuppressant therapy have considerably improved the prognoses in this patient affected by severe disease with complete remission as confirmed by long term followup. Appendectomy and gastric suture were the onset treatments. We are usual to pharmacological treatment of EGPA, but the presence of appendicitis and gastric perforation needed surgical treatment to save the life of the patient. The clinician and the surgeon synergistically worked to treat the same pathology. The outcome was the complete recovery of the patient as regards clinical symptoms, laboratory test and organ healing.

\section{Conflict of interest}

\section{None}

\section{References}

1. Mouthon L, Dunogue B, Guillevin L (2014) Diagnosis and classification of eosinophilic granulomatosis with polyangiitis (formerly named Churg-Strauss syndrome). $J$ Autoimmun 48-49:99-103. [Crossref]

2. Sablé-Fourtassou R, Cohen P, Mahr A, Pagnoux C, Mouthon L, et al. Antineutrophi cytoplasmic antibodies in Churg-Strauss syndrome. Ann Intern Med 2005; 143: 632e8. [Crossref]

3. Lally L, Spiera R (2015) Current therapies for ANCA-associated vasculitis. Annu Rev Med 66:227-40. [Crossref]

4. Guillevin L, Pagnoux C, Seror R, Mahr A, Mouthon L, et al. (2011) The Five-Facto Score revisited: assessment of prognoses of systemic necrotizing vasculitides based on the French Vasculitis Study Group (FVSG) cohort. Medicine 90: 19-27. [Crossref]

5. Ribi C, Cohen P, Pagnoux C, Mahr A, Arène JP, et al. (2008) Treatment of Churg-Strauss syndrome without poor-prognosis factors: a multicenter, prospective, randomized, open-label study of seventy-two patients. Arthritis Rheum 58: 586-94. [Crossref]

6. Gayraud M, Guillevin L, le Toumelin P, Cohen P, Lhote F, et al. (2001) Long-term followup of polyarteritis nodosa, microscopic polyangiitis, and Churg-Strauss syndrome: analysis of four prospective trials including 278 patients. Arthritis Rheum 44: 666-75. [Crossref]

7. Thiel J, Hässler F, Salzer U, Voll RE, Venhoff N (2013) Rituximab in the treatment of refractory or relapsing eosinophilic granulomatosis with polyangiitis (Churg-Strauss syndrome). Arthritis Res Ther 15: R133. [Crossref]

8. Groh M, Pagnoux C, Baldini C, Bel E, Bottero P, et al. (2015) Eosinophilic granulomatosis with polyangiitis (Churg-Strauss) (EGPA) Consensus Task Force recommendations for evaluation and management. Eur J Intern Med 26: 545-53. [Crossref]

9. Wechsler ME, Akuthota P, Jayne D, Khoury P, Klion A, et al. (2017) Mepolizumab or placebo for eosinophilic granulomatosis with polyangiitis. N Engl J Med 376: 1921-32.

10. Ha HK, Lee SH, Rha SE, Kim JH, Byun JY, et al. (2000) Radiologic features of litis involving the gastrointestinal tract. Radiographics 20: 779-94.

11. Ahn E, Luk A, Chetty R, Butany J (2009) Vasculitides of the gastrointestinal tract Semin Diagn Pathol 26: 77-88.

Copyright: (C2017 Gioia G. This is an open-access article distributed under the terms of the Creative Commons Attribution License, which permits unrestricted use, distribution, and reproduction in any medium, provided the original author and source are credited. 